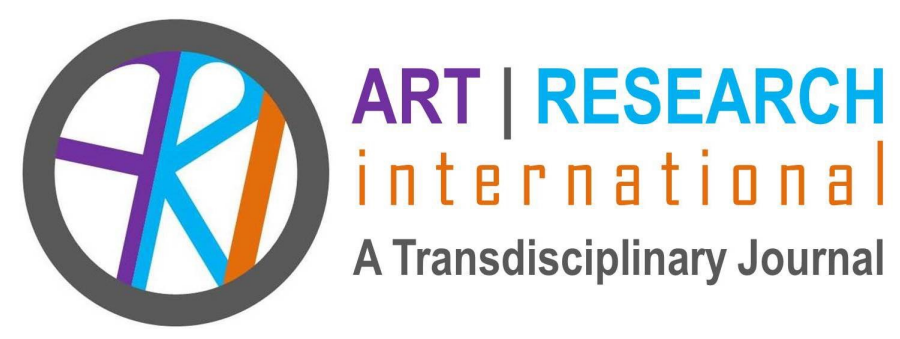

\title{
WOVEN NARRATIVES: A CRAFT ENCOUNTER WITH TAPESTRY WEAVING IN A RESIDENTIAL AGED CARE FACILITY
}

\author{
Ilona Pappne Demecs \\ Queensland University of Technology \\ i.pappnedemecs@hdr.qut.edu.au
}

Evonne Miller

Queensland University of Technology

e.miller@qut.edu.au

Ilona Pappne Demecs is a PhD candidate in the School of Design, Creative Industries Faculty at Queensland University of Technology. Her research interest includes art-based research and participatory art in various health and aged care contexts.

Evonne Miller is an Associate Professor and the Director of the Queensland University of Technology Design Lab in the Creative Industries Faculty. Her research focuses on how environments can better support users, especially older people, and on the potential of creative and visual methodologies in aged care.

Abstract: For six months, a tapestry artist/researcher moved her studio into an aged care home to conduct a participatory art project. Drawing on ethnographic-based qualitative approaches, narrative inquiry and researcher-generated photographs, this arts-based research textually and visually documents the impact of introducing the studio-based craft activity of participatory tapestry weaving into an aged care environment. As well as highlighting the joy of creative collaboration and of learning a new skill, this project explores 
how tapestry weaving facilitated the understanding of the participants' worlds through stories and reminiscence. This paper also disseminates that craft, as a practice and method, connects materials, ideas and people through engagement, and facilitates wellbeing. Given rapid population ageing, and the fear and stigma surrounding aged care homes, this paper argues that craft practice might help demystify and connect aged care with the broader community, as well as enhancing residents' quality of life.

Keywords: tapestry weaving; studio craft; participatory art; creativity; residential aged care facility 
09:00am. Setting up the loom in low-care facility at the lunch room. Residents started to arrive for their morning tea and while waiting, they sit in front of the TV. A carer helped Thelma to come out from her room, and she sat down with the other residents. As soon as Thelma sat down, she started to knit while she was waiting. I noticed that she did not watch her knitting, she just sat and uninterruptedly chatted with residents while with her hands she was busy knitting. I thought, yes, a resident who is interested in craft. I went and introduced myself, explained why I was there and politely invited her to the loom to observe and maybe do some weaving. I also asked her what she was working on. Thelma listened to me with interest, while she was still knitting. "I am making a jumper for my great grandchild," she replied. She shyly told me that she would be very much interested in my weaving project, because she had done lots of craft - but nowadays, she could only do craft which she remembered by heart, because she was blind. (9.00am, 13 July, 2016. Field notes IPD)

\section{Introduction}

The above field notes, taken as part of a participatory art project in an aged care home, highlight how blind, 101-year-old Thelma still experiences significant joy and personal meaning from engaging with craft. ${ }^{1}$ Like Thelma, throughout their lives, many people derive great enjoyment from the immersive multi-sensory experience of craft - the practical and personally creative experience of making and creating something with our hands. From the soft touch of wool and the clicking of knitting needles to the cool feel of clay between fingers, the embedded tactic knowledge, repetitive practice, and creative making processes of craft are deeply experiential, calming and meaningful. In contemporary residential aged care, craft is a common activity. Similar to Thelma, many older female residents often use the familiar craft skills of knitting or crocheting to keep themselves useful and busy, creating functional, yet aesthetically pleasing objects made with love for family members, friends and charities. Engaging in meaningful occupations in residential aged care is not only a personal choice for many residents, today, it is also a formal part of best practice policy. In Australia, for example, the National Institute for Health and Care Excellence (NICE, 2013) identified providing opportunities to participate in meaningful activities as a key factor that contributes to a sense of purpose, consequently improving residents' quality of life. While engagement in any activity is usually beneficial (Miller, 2016), recent research has highlighted that the type of activity older aged care residents engaged in (for example, whether it is physical, cognitive or creative) might influence wellbeing differently. This growing body of literature shows the unique value of participating in creative activities in old age, especially craft (e.g., Fraser, Bungay, \& Munn-Giddings, 2014; Kim, 2016). However, it is important to acknowledge that in everyday practices, meaningful creative activities are not readily available for residents in aged care homes due to limited resources, including trained staff. 
Qualitative research shows that the limited activities resulted in most residents being bored and desiring more interactive, creative and intellectually stimulating programming (Choi, Ransom \& Wyllie, 2008; Miller, 2016; Timonen \& O’Dwyer, 2009).

\section{In our hectic, technologically} connected world, the process of

In our hectic, technologically connected world, the process of "making and creating" craft (whether it is knitting, crochet, weaving, sewing, needlework, or jewelry) is therapeutic. Research has highlighted how people with depression benefit from needlework, as the process of concentrating on a "small slow piece of work absorbs [the] mind and soul" (Reynolds, 2000, p. 10), as well as how the experience of knitting provides a place of calm, an escape from anxiety, physical and mental pain (Turney, 2009).

Craft can also be provocative and thought-provoking, providing a novel way to reach and engage the general public, authorities, and decision-makers. For example, in a creative collaboration between scientists and artists, the concrete and textile dress Herself was designed to explore the potential of a material that purified the air (Belford, 2013). More recently, as part of the Women's March on Washington, knitters, sewers and crocheters made and distributed over 100,000 pink "Pussyhats" in response to President Trump's 2006 comments about sexual assault (where he just grabs women "by the pussy"). A powerful example of craft activism, the "Pussyhat" project illustrates how women's traditional domestic crafts are being reframed as tools for feminist social change (Black, 2017).

On a smaller scale, our project also uses craft to draw attention to a topic and experience many people fear and know very little about: daily life in an aged care home. Significant stigma surrounds any decision to move to aged care, with older people afraid of "ending up there," families feeling guilty for considering aged care as a housing option, and many healthcare professionals viewing aged care negatively (Higgs \& Gilleard, 2014; Productivity Commission, 2011). Despite significant reform, aged care is still commonly disparaged as "God's waiting room." Indeed, American research found people were more fearful of life in a nursing home than their own death (Prince \& Butler, 2007).

Thus, our intentions in doing this research and writing this paper are twofold. First, at a broad level, the core aim was to use participatory craft to challenge dominant stereotypes and assumptions about old age, frailty and participation, disrupting the institutionalized, routine-driven aged care environment. For six months, the artist/researcher (Ilona) moved her studio and large loom into an aged care facility, working side-by-side with older residents 
to co-create and co-weave a tapestry - the Tapestry of Home. Second, and more specifically, this paper draws on field notes, interviews, and researcher-generated photographs from this experience to share how this unusual craft activity positively disrupted the rhythm of daily life in residential care, as well as the impact on residents, staff, and the researcher/artist. Grounded in principles of participatory research and coproduction, this research purposely uses a rare craft (tapestry weaving) that develops at a slow pace, enabling conversations, connections, and suiting the slower pace of older age. As Charmaz (2004) noted, we must engage in our participants' world, whether that is to "slow down to the world of institutionalised elders or speed up to the pace of corporate executives" (p. 983). The following sections briefly review the literature in this space, highlighting the importance of craft for health in older age, before introducing the Tapestry of Home project in more detail.

\section{Creative Activities in Old Age}

Despite craft-based activities being common in the everyday context of aged care, residents' craft experience has been given little research attention. Studies that describe the beneficial outcomes of craft participation in old age are typically conducted outside the aged care context. For example, numerous studies have described how participation in craft activities (especially in later life) can increase life satisfaction, with positive effects on psychological health - reducing depression and anxiety, and fostering feelings of happiness, calmness and relaxation (Reynolds \& Prior, 2006; Reynolds, 1999; Riley, Corkhill, \& Morris, 2013). As well as being linked to enhanced developmental and learning outcomes (Maidment \& McFlare, 2011), lace making contributed to health and wellbeing, enhanced self-esteem and identity, learning growth and belonging for older community-dwelling women (Kenning, 2015).

\section{Tapestry Weaving}

When compared to an everyday craft (such as knitting, crocheting, embroidery etc.), tapestry weaving can be categorised as a studio craft and therefore the general public is less familiar with it. Historically, in addition to offering enjoyment of its aesthetic qualities, it also offered unlimited ways for communication, expressing cultural and personal identity (Deacon \& Calvin, 2014; Riley, 2008). Dating back to the Neolithic era, the basic structure of weaving remains unchanged: the combination of the vertical wrap and the horizontal weft on a frame (a loom) through a sequential form of pre-planned and visualised textile creation builds from the bottom up. The process of designing and creating a woven tapestry is dialogic, visual and time-consuming. Over the last few decades, tapestry weaving has been 
revived as a tool for community engagement and collaborative story telling. Tapestry makes an excellent medium for community art, as (1) the public can be involved in all stages in the development of the artwork, (2) the making processes are a shared work, between the designers, the drawers and the weavers, and (3) as being a textile craft people may respond positively to the tactile, soft nature and visual elements of tapestry craft (Darlaston, 2013; Penney, 2011). Two notable examples of the international community tapestry movement (where the public are invited to sit with the artist and weave their story into a tapestry) include the large Canberra Community Centenary Tapestry in Australia $(2.4 \mathrm{~m} \times 1.4 \mathrm{~m}$, created over 15 months) (Lindsay, n.d.) and a Canadian travelling workshop, the Big Weave that attracted up to 90 people a day (Ewens, 2009).

\section{The Design Considerations of Tapestry Weaving in Aged Care}

Within the participatory design approach, designing the activity was a crucial part of the project with many considerations made before taking the project out to the community. Theoretically, this project was inspired by Frankl's (1992) theory of meaning and the gerotranscendence theory (Tornstam, 1997). Frankl's theory of meaning defined the importance of purpose, specifically meaning. In the context of aged care, meaningful activities are essential for quality of life. In this project, the meaningful activity was embedded in a creative collaboration project, explicitly, the presence of the tapestry-weaving studio provided meaningful engagement opportunities for the community of aged care for an extended period of time. Tornstam's concept of gerotranscendence argues that by taking an optimistic view in the final development stage of human life, older people can experience transcendence - a process which can be accelerated by meaningful activities.

Methodologically, the project was guided by Nolan's (1996) six senses framework. This framework emphasizes six important "relationship-centred care" points to consider when working with an older person, specifically: providing a sense of security, continuity, purpose, belonging, fulfillment and a sense of significance. In this project, residents joined voluntarily, considering their daily and constantly changing physiological and psychological capabilities. This engendered a sense of safety, as the older person dictated their degree of participation - whether it was watching and commenting, or actively participating in the creation and weaving. The sense of continuity and purpose was fulfilled by the concept of the artistic design, as well as the longitudinal nature of the project. This participatory art project was designed to involve the whole community of the aged care home, with co-designing the tapestry as well as working on the loom simultaneously together providing a sense of belonging. The sense of purpose in this project was to co-design and co-create a meaningful art object. The sense of fulfillment was found by doing a simple craft activity (weaving), but 
applying it in a way (tapestry weaving), enabling residents to learn a new skill. And, finally, the sense of significance was achieved through involving residents in a creative and unusual art project which they could personalise - residents co-designed the tapestry narrative, knowing that their personal stories and experiences would be shared publicly when the final tapestry was exhibited in libraries, forums, conferences and universities.

Secondly, there was a need to provide several entries for participation (any time, for any amount of time) to maximize the creative opportunities within the scheduled life style of aged care. There was also a graduated approach to participation throughout the project, with the tapestry starting in the artist/researcher's studio where the border was woven. The loom and tapestry were then placed in the facility, with a plan to collaboratively complete the design through three phases. The first phase was the Connection. This was designed to build relationships, trigger conversation and encourage engagement within the community, through the artist sitting and weaving. This was based on the idea that an "art encounter" has the potential to create a "special space" where creativity can be prompted, and, beyond simple information, sensuous knowledge can emerge or subjective knowledge can be explored (Darlaston, 2013; Hogan, 2015; O’Neill, 2008).

The second phase was the Collaboration. This provided a platform to co-design the tapestry and shared design options, ideas and sketches. Like every woven tapestry, this tapestry also had a story line - not just for the topic of the work, but as a participatory art project there was a need for a point of connection for the participants. The idea of home was chosen as a guiding focus by the artist, collecting the stories of "meaning of home" as a way to represent the past, the present and the future, as well as the places and the people who were involved in the making of the tapestry. The past was stories that came from residents' life histories (from their homes where they used to live), the present was the life which was happening in their current aged care home, and the future was the created tapestry which will forever carry the stories created by them.

The third phase was the Creation, during which the weaving process took place. This phase was the longest, due to the slow nature of the weaving process (a small $10 \times 10 \mathrm{~cm}$ square takes 1 to 2 hours). In this phase, participants were able to learn new skills and contribute to the progression of the tapestry by doing, producing and creating; transforming the raw material it into something that did not previously exist.

As well as textually and visually documenting how an aged care community responded to the presence of a large loom in their communal living rooms and engaged with a studio-based craft activity, this paper explores how the Tapestry of Home project created a "potential space" for residents (as well as staff and visitors) to engage and involve in multiple 
levels of creativity in the sensuous and sensory experience of storytelling through collaborative weaving. This unusual craft encounter, and the creative making and narrative sharing process of tapestry weaving, became a place of daily joy and wellbeing for older aged care residents.

\section{Methodology and Methods}

The Tapestry of Home project was conducted within the frame of ethnographic fieldwork. Ethnography allows sustained participant observations that can reach interpersonal dimensions of activities, which unfold from moment to moment (Desmarais, 2016). In this research, embedded observation was important to examine the process and the transformations along with the properties of engagement and making.

The core of creative practices is immersing in art as a way of generating knowledge. In creative practices, the artist conducts the research conversations with items of material culture and creates a fluid collaboration described as material thinking by Carter (2004). He conceptualises making as a relational activity through which knowledge is generated. There is a conversation "kind of an exchange" embedded in the making process, which takes the researcher on an adventure of knowing (Carter, 2004). In participatory art practice, and specifically in the Tapestry of Home project, the material thinking - "makingly knowing," was created from the participants' knowledge of their experiences, generated through the process of meeting (encounter) and making the tapestry.

To formulate these experiences, we present the data through the participants narratives. Clandinin and Huber (2010) argue that narrative inquiry is "inquiring into experience through collaboration between researcher and participants over time in a place" (p. 436).

\section{Case Study Site}

The first step to making this project a reality was to find a host facility that (1) was within a one hours drive of the artist/researcher's home, and (2) would accommodate an artist with a loom for several months. The participating not-for-profit facility has 200 aged care rooms and a separate dementia care unit, allows pets to stay with the residents and has a pool, bird house, a coffee shop and a hairdressing salon. 


\section{Procedure}

Standard practice ethical protocols were followed, with formal ethical clearance obtained from the university human research ethics committee (\#1500000343). Written informed consent was obtained from each participant, who chose their own pseudonym and approved the publication of all images. Flyers explaining the project were displayed around the case study facility, with residents and staff invited to an initial meeting explaining the project and providing project information packages to potential participants - all interested residents with the cognitive capacity to participate. The facility has three different levels of care buildings, and management requested that all residents had the opportunity to participate in the making of the tapestry. Fortunately, the $1.8 \mathrm{~m} \times 2 \mathrm{~m}$ loom had wheels on it, and was able to be rotated across each building: the high care centre on Mondays, mixed care (low and high care) on Tuesdays, and respite and low care centre on Wednesdays. With the exception of three group meetings at the beginning to decide on an overall aesthetic design and plan for the tapestry, the process for participation and engagement was very informal and iterative. On the allocated day, the loom was simply set up in a well visible and approachable corner space in each facility and residents (and staff and visitors) engaged as they wished. On a typical day, 10 residents engaged with the loom and the tapestry-weaving project.

\section{Data Collection and Analysis}

The data collection was parallel and continuous throughout project. For this paper, data was drawn from "field worker first-hand experience;" the artist/research made observations, field notes, videos and photos during the project. The observation and the field notes were written after each loom session, and matched with video recordings of informal conversations at the loom and more formal semi-structured interviews (typically in participants bedrooms). The data was manually analysed for recurrent themes by both authors, using Riessman's (2008) flexible narrative approach to understand how participants' stories were related to their participation in the tapestry-weaving project. Data was coded openly, using thematic analysis (Braun \& Clarke, 2006). During the coding process, the participantselected pseudonym was assigned and any uniquely identifying material removed. Next, the process of deep data immersion continued through close reading and re-reading of the observations, the field notes and examination of photographs. Potentially significant excerpts were highlighted and coded, line-by-line, shaping further analysis. Key photographs were grouped. Initial thoughts, codes, and notes were transformed into emergent themes. Finally, themes were clustered to identify shared meaning, alongside associated photographs. These themes are discussed and grouped under the three-layered participation structure 
that guided the design and delivery of the Tapestry of Home project - starting with connection (connection through curiosity), to collaboration (creative collaboration, inspiration and expressing imagination) and finally, ending with creation (the joy of creating, making, and aesthetic indulgence).

\section{The Narratives}

\section{Theme 1: Connection through Curiosity}

During the initial connection phase, the field notes and observations were very similar throughout the facility. The "craft encounter" of placing the loom in the facility and simply doing the weaving generated much curiosity about the project. People gathered around the loom in groups; residents, visitors and staff all wanted to know what was happening and why. In some cases, the novelty of the project disrupted the routine of aged care and resulted in unusual responses. As an example, Figure 1 and the field notes below illustrate what happened the first day the loom was set up in the high care facility.

Two female residents Rose and Jade, both in mobility aids, asked the staff to bring them to the loom. When they arrived, they enthusiastically told me that they were waiting to meet me and see the loom. They took special interest in the weaving and kept asking questions about the project: "What are you doing? Why did you come here?" I explained the project and invited them to come closer, so they could see the weaving process, because they both told me that they had never seen such weaving before. They also spontaneously started to talk about their experiences of craft. Rose explained that she started to sew when she was a school age girl; she learned to make clothes helping her mother make clothes for her siblings. Jade, similarly, was familiar with other craft skills: knitting and crocheting, and used to

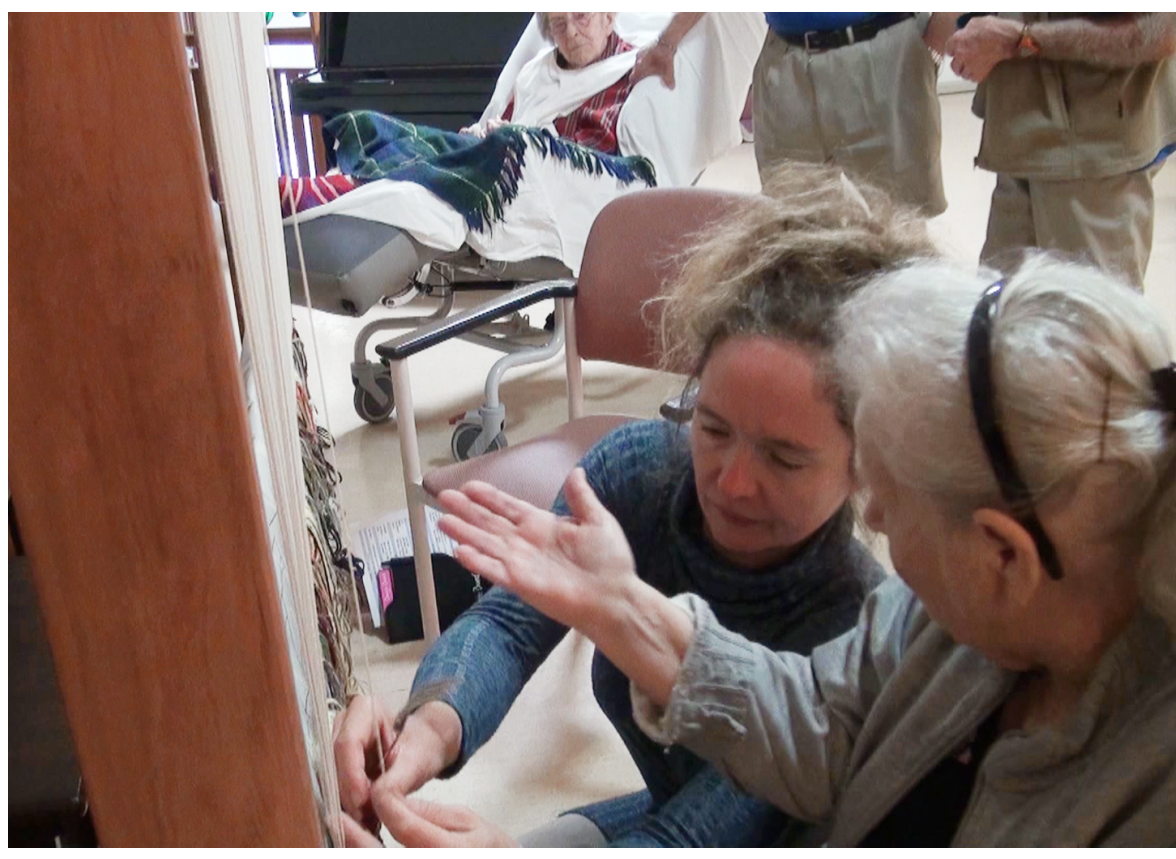

Figure 1. Rose and Jade arrived at the loom 
make clothes for her own children. They said that they had never done any kind of weaving, especially not tapestry weaving. Occasionally, passing staff members also commented on the weaving: "That looks great, how cool," but they did not stop for longer conversation (09.30am, 11 July 2016, field notes IPD).

At this point of the project, the loom and the unusual weaving activity recaptured people's creativity through curiosity. Kim (2016) writes that curiosity is one of the key roles in creativity, as the human mind needs to be open to new experiences and willing to ask questions which could lead to more challenges. Similarly, Csikszentmihalyi (1996) describe curiosity as a foundation of creativity when people are open to investigation. Beyond curiosity, however, people who came over to look at the loom were inspired to talk about and share their craft experiences. The stories at the loom were subjective, informative and often traditionally and passionately interwoven. Similar to Rose, stories from other residents frequently emphasised how craft in "their time" was often a necessity, as they made clothes for family members for practical and economic reasons. Culturally embedded stories also came from staff and residents who were born overseas. For example, Figure 2 shows how one staff member shared with pride her memories of how, as a small girl, she used to watch her grandfather (who was born in the Torres Strait, remote Australian island clusters) weaving with natural fibre.

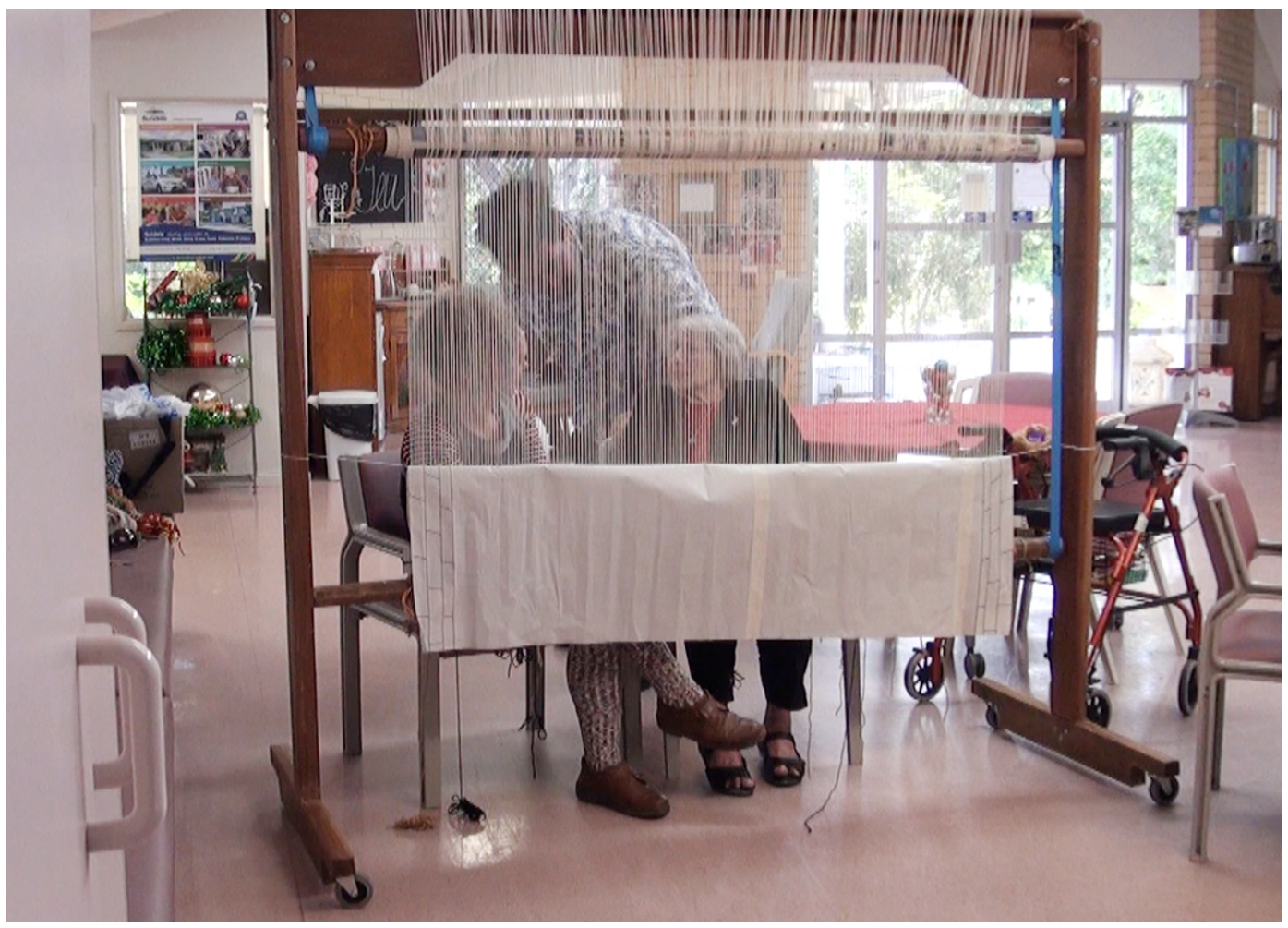

Figure 2. Staff sharing memories 
Sitting at the loom, a female resident named Clara, who was born in the Netherlands, became unusually lively as she recognised a long unseen craft, fondly sharing how she had once worked on a project: "This is very similar to the work I used to help with. We were weaving a tapestry for Queen Juliana." This memory inspired her to try to do weaving again and while we were weaving she became so happy she spontaneously started singing songs from her home country at the loom (Figure 3). The presence of the loom also stimulated the staff; one of the activity coordinators busily took many photos of residents interacting with the loom. She later explained that one of the ladies (the lady in the hat, Beryl - see Figure 4) who was so interested and engaged in conversation, normally never left her room, and it was highly unusual to see her show interest in any activities.

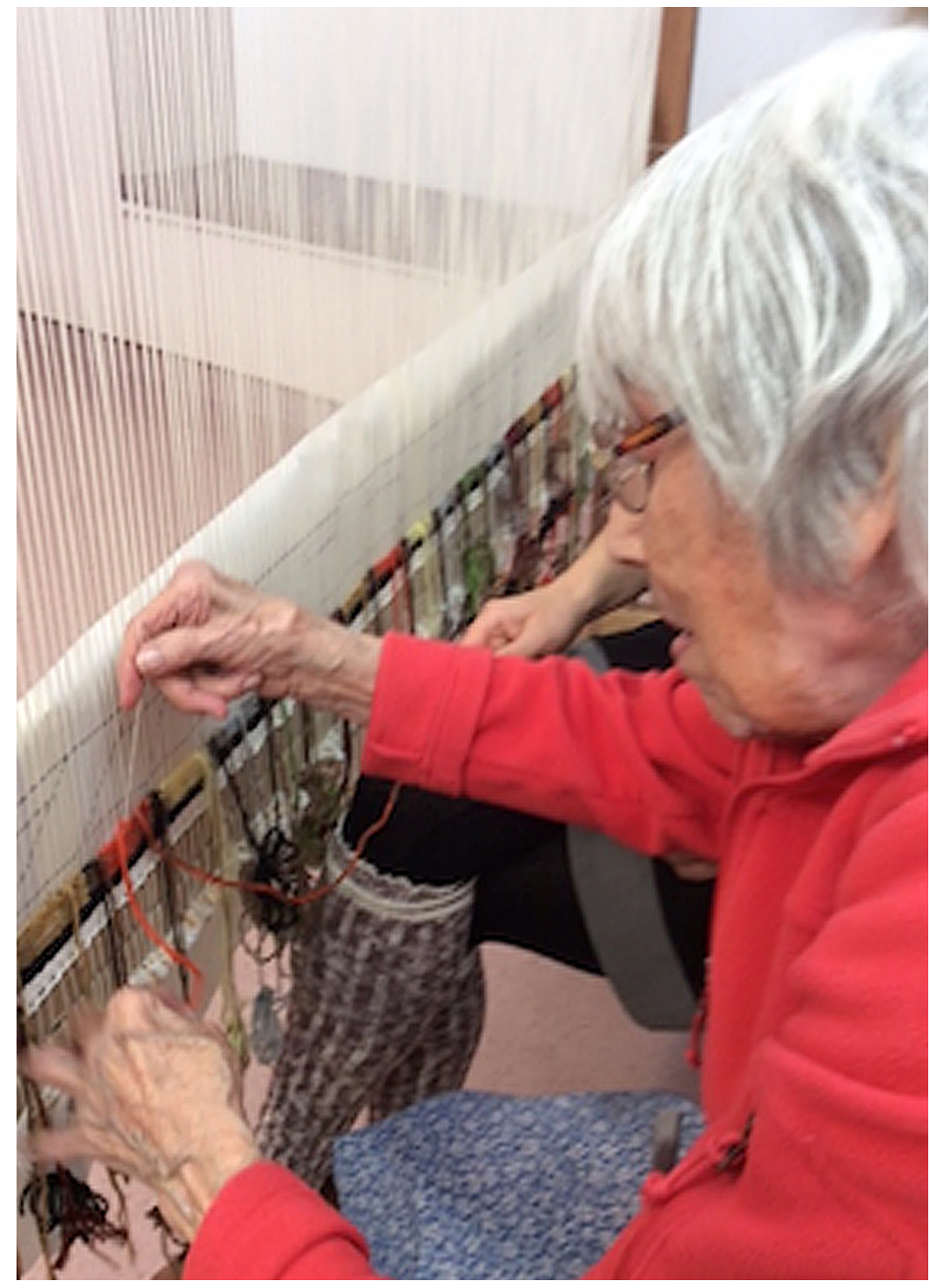

Figure 3. Clara engaged with weaving while she sang 
Craft is often a highly valued indicator of personal, cultural and collective identity, triggering the recollection and discussion of past lives, activities and memorable moments. Here, the presence of a textile craft brought together the community of the facility, as residents and staff shared the many stories that have the common thread of connection to craft. Indeed, research frequently documents the link between stories and craft. Drawing on Walter Benjamin's (Benjamin \& Arendt, 1987) theoretical work of craft making, Leslie (1998) described craft making as an experience of sharing and telling, which has a strong association with storytelling. Leslie argued craft making encourages storytelling at multiple levels; it provides a physical opportunity to tell a story, but the stories will also be incorporated into the object, which in turn will tell the story to the wider world. In this way, the stories create a space of sharing and learning about cultural values and/or traditions.

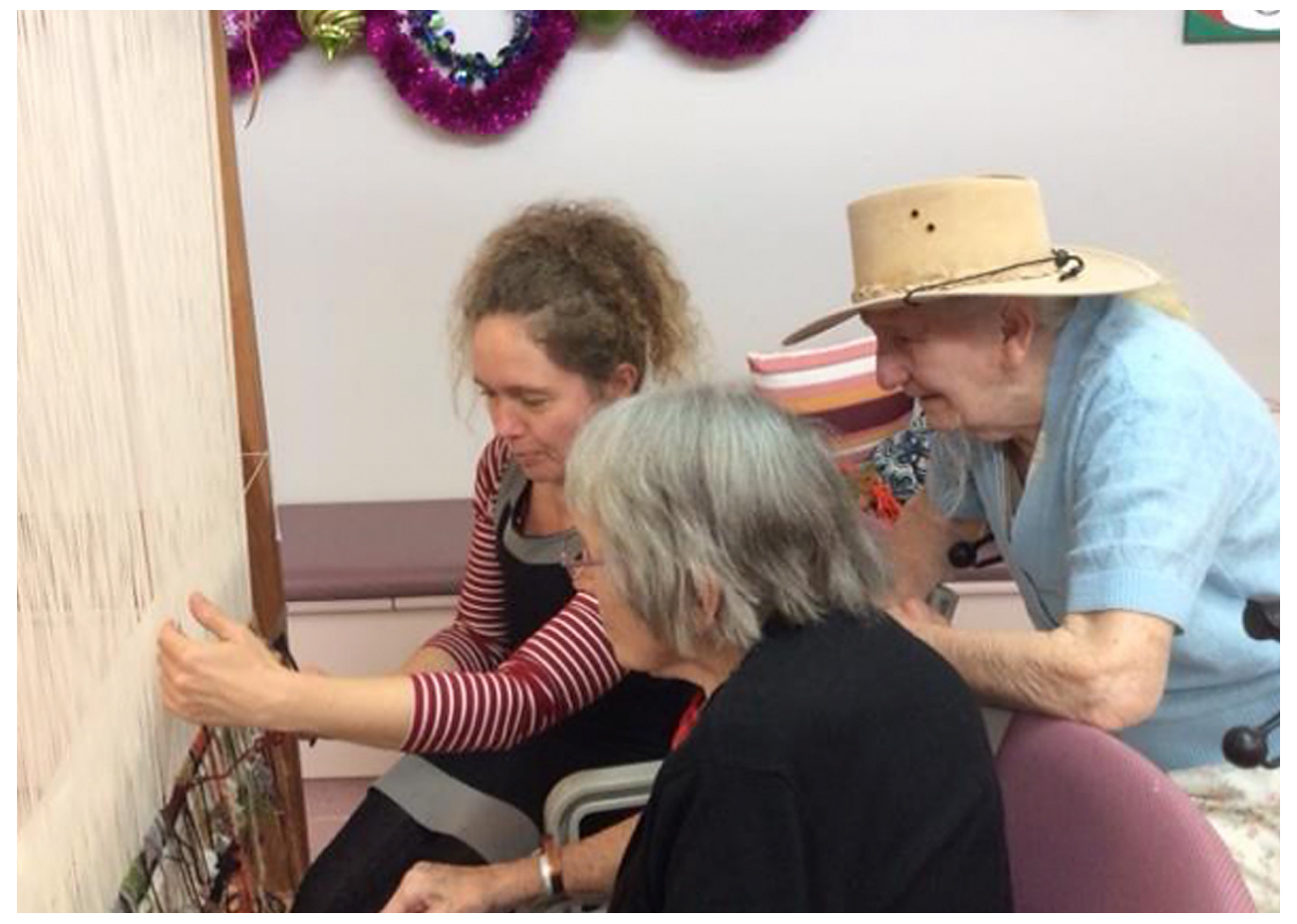

Figure 4. Beryl looking at the loom

Through the stories, the tapestry loom also became a space for remembering, a process which can reinforce powerful human feelings at any time in our lives (Adeniji-Neil, Concannon-Gibney \& Weida, 2014). In old age, however, reminiscence and storytelling also have strong connections with healthy psychological growth. Building on and expanding Erikson's (1950) seminal model of psychosocial development theory, Cohen (2009) identified four phases of old age. He called the third phase the "summing up phase" (generally from the late 60 s to 80 s), when people look back and are motivated to share their experiences/ wisdom. The loom and the tapestry project gave these older aged care residents a valuable chance to do that - to reflect, "sum up" and share their meaningful experience with craft over their lifetimes. 


\section{Theme 2: Creative Collaboration, Inspiration and Expressing Imagination}

By the time of the collaboration phase (2 weeks into the project), the community were familiar with the loom. With the co-operation of the activity coordinators, meetings were arranged with residents where we gathered ideas about the tapestry design. Over 30 residents from across all the buildings came to share their thoughts and interpretations on the meaning of home, contributing to the tapestry design. The designing phase was the most popular phase, with residents delighted to express their ideas and give their contributions to the art piece (see Figure 5). In the design phase, multiple ideas about the meaning of home were gathered. Most residents suggested concepts that were connected with the outdoors, for example, mountains, river, flowers, animals and sky. Similar to the connection phase, the stories reached back to the past and formulated their expressions of meanings of home.

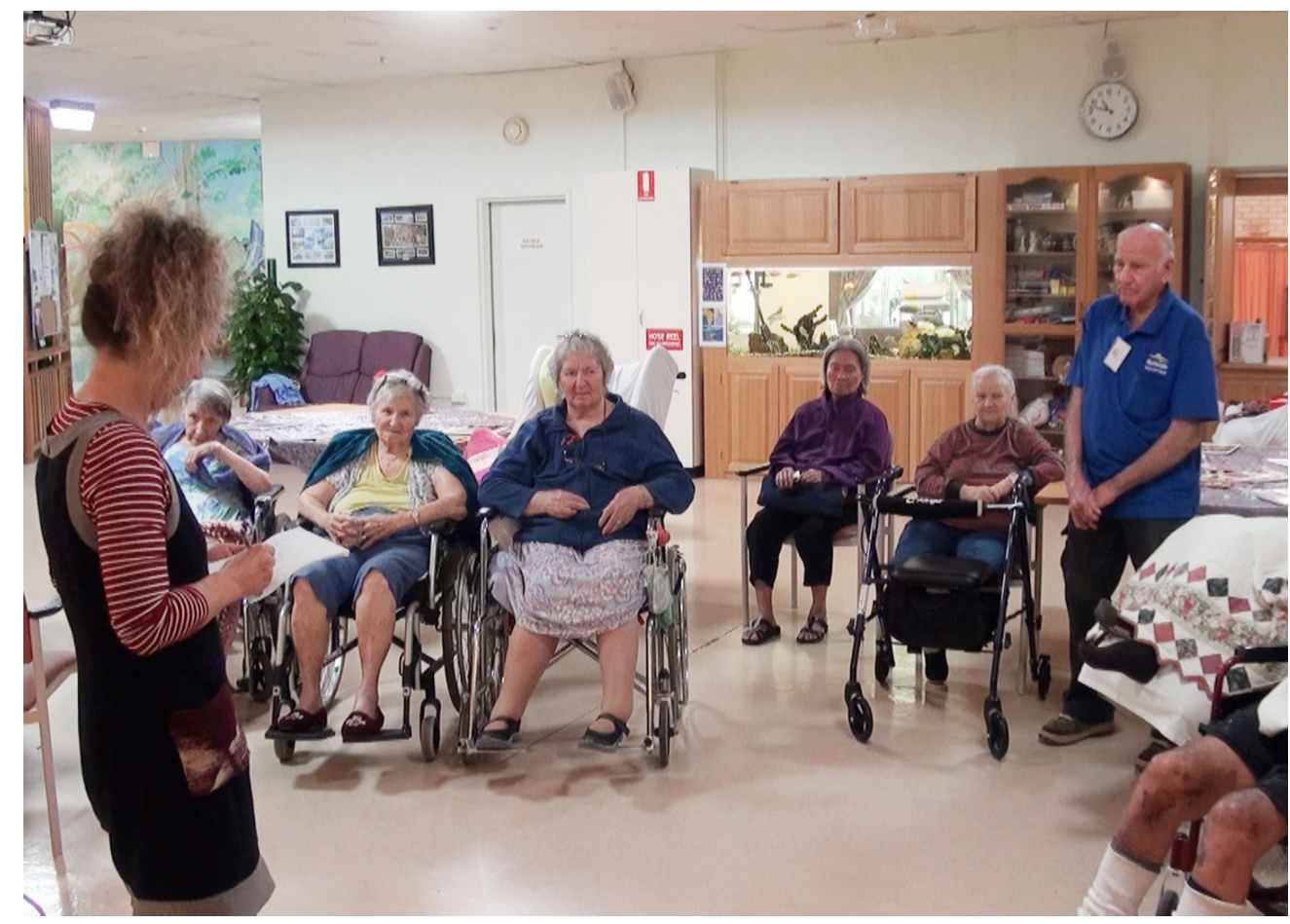

Figure 5. Collecting ideas at the loom

Personal stories from their youth were also shared. For example, Nancy talked about the river from her country home, which was an important landmark of both necessity (providing water for the animals) and joy (swimming). During the subsequent conversation of the nature around their homes, other residents (such as Jack and Alpal) discovered a point of interest and information they did not know about each other before. Residents were delighted when they talked about past memories, preferred and significant features, with Heather (who had resided in the home for 15 years) sharing her love of flowers: "I always 
loved daisies and I would love to see some daisies on the tapestry." Sitting in a semicircle, these personal stories were shared, facilitating an understanding of each other's pasts and passions (see Figure 6).

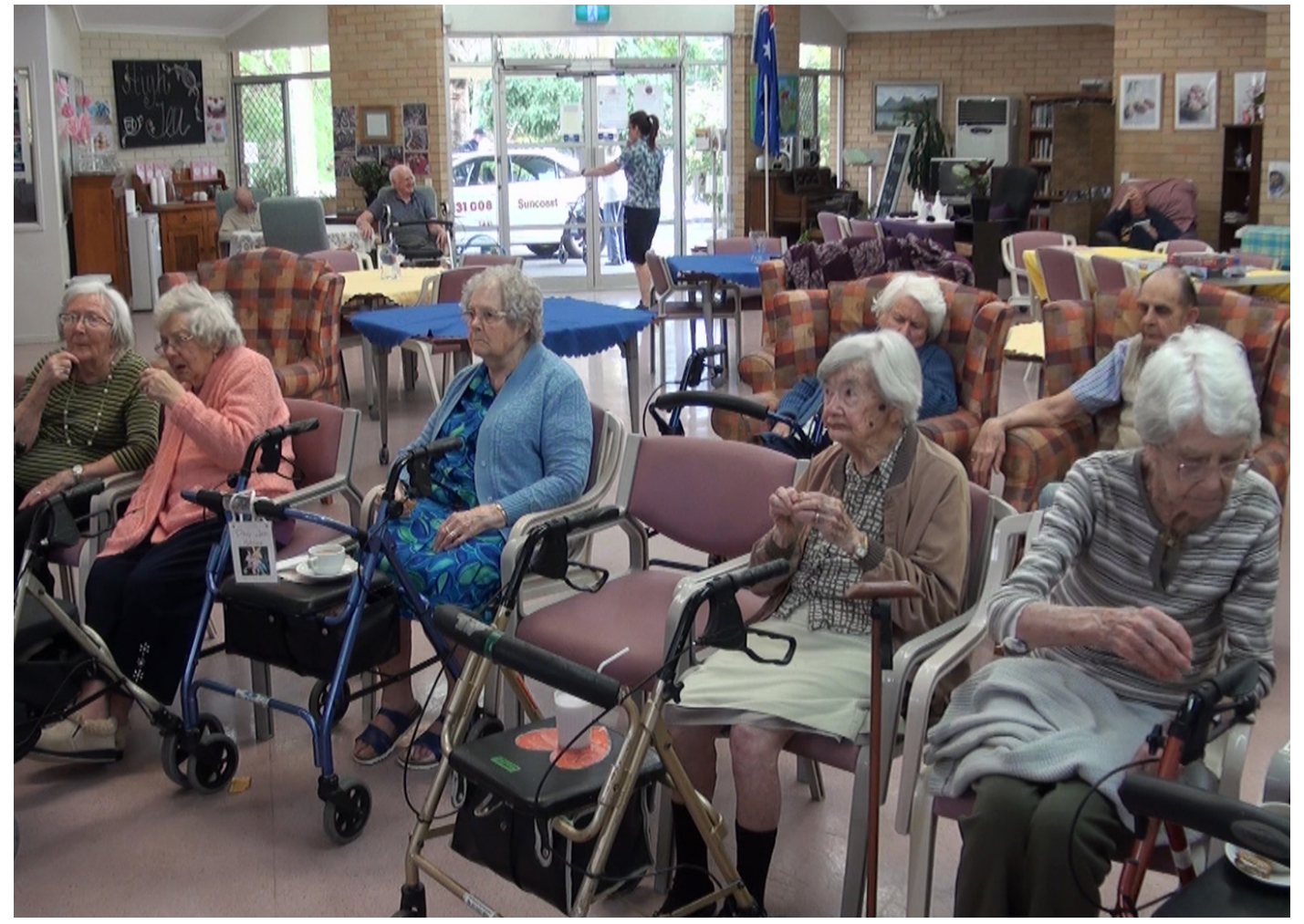

Figure 6. Heather in pink jumper, requesting daises

In expressing their unique creativity, residents also added special touches to the design. A point of interest was the dog residents wanted woven into the tapestry; residents expressed their national identity by likening its resemblance to a kangaroo - an iconic symbol of Australia. The process of designing truly engaged the imagination of the residents. And, as Riley (2008) reminds us, imagination is essentially connected to creativity in craftsmanship as it is the driving force of the design process. The use of imagination also plays an important role in creating specific design elements, which in the craft object, is often the defining element of the social group creating it (Adeniji-Neil, Concannon-Gibney \& Weida, 2014).

The final touches of the design were done after the artist/researcher drew up the elements of the tapestry. The residents chose the colours for the picture, colouring in the pre-drawn design. The pre-drawn design was handed out to residents (approximately 30 were taken and 21 were returned) for colouring in. By this point of the project, some residents expressed significant enthusiasm about participating. Rita, who had severe 
arthritis, enthusiastically contributed to the coloring in, leading one staff member to comment that she had never seen her participate in activities with such enthusiasm (Figure 7). After the individual colorings were completed, there was a last meeting to finalize colour selections before the weaving commenced.

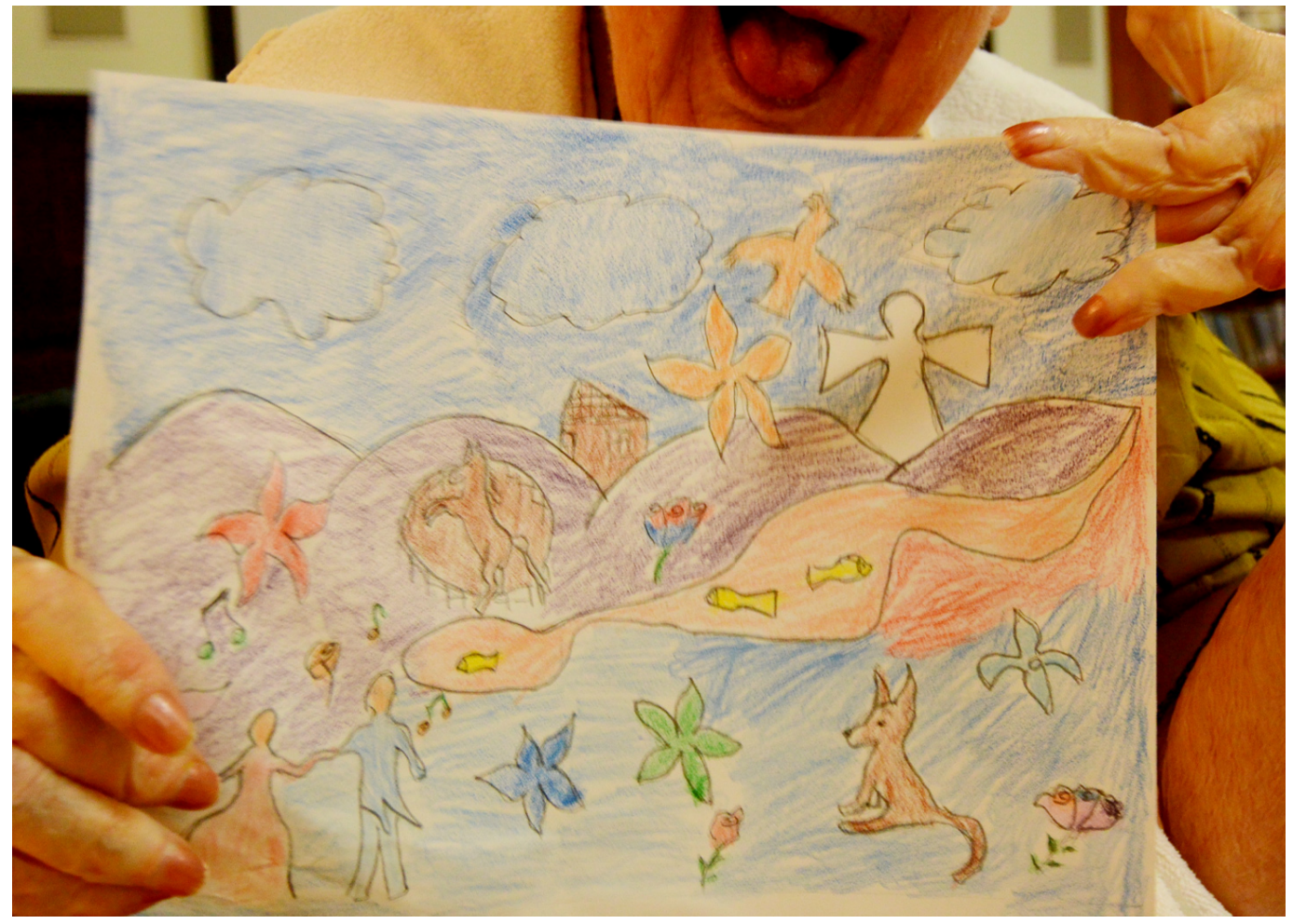

Figure 7. Rita holding her tapestry design

\section{Theme 3: Creation - The Joy of Creating, Making and Aesthetic Indulgence}

During the creation phase, the loom was wheeled between the facilities daily. The aged care community eagerly anticipated what the final tapestry would look like. It was time to directly experience how the wool in tapestry weaving mixes together, and how the shapes of the design will be formed. In this phase, the "mystery of tapestry weaving" was slowly revealed, and participants came to appreciate that tapestry is invested with skill and the time taken to construct a complex fabric with a myriad of weft threads (every weft passes over a warp).

For learning a new skill, the craft of tapestry weaving appealed to many residents. For some, it became a passion. One exceptional case was Lorna. Through persistent work, Lorna mastered the skills of tapestry weaving and greatly enjoyed her participation - to the extent that she did not want to do other activities, as she explained: "This is what I want to 
do now." Lorna chose to weave every Tuesday morning, wanting to stay longer and longer at the loom. She started requesting that the artist stay for the afternoon or come back on other days; she also put off leaving the loom (for example, delaying going to lunch or the bathroom) to the last minute. While everybody else was getting ready for lunch, Lorna kept weaving and simply lost interest in other important tasks. She was experiencing the joy, the flow, of creative making.

Multiple scholars (e.g., Maidment \& McFlare, 2011; Pöllänen, 2015) have explained that one key positive outcome of craft activities is that they are strongly connected to Csikszentmihalyi's (1996) concept of flow. Repetitive activities, such as craft, have a strong association with enhancing the sense of "flow" and can, especially in old age, contribute significantly to subjective wellbeing (McHugh, 2016). Beside the satisfactory repetitive motion of craft making, Kim (2014, p. 63) argues that handling a raw material enables a "sense of cognitive and physical challenge," and when "moulding it to our purpose" there is an "unmistakable satisfaction, assertive self-reliance, self-affirmation and even empowerment" in making. As Figure 8 illustrates, Lorna experienced this through her engagement with the loom.

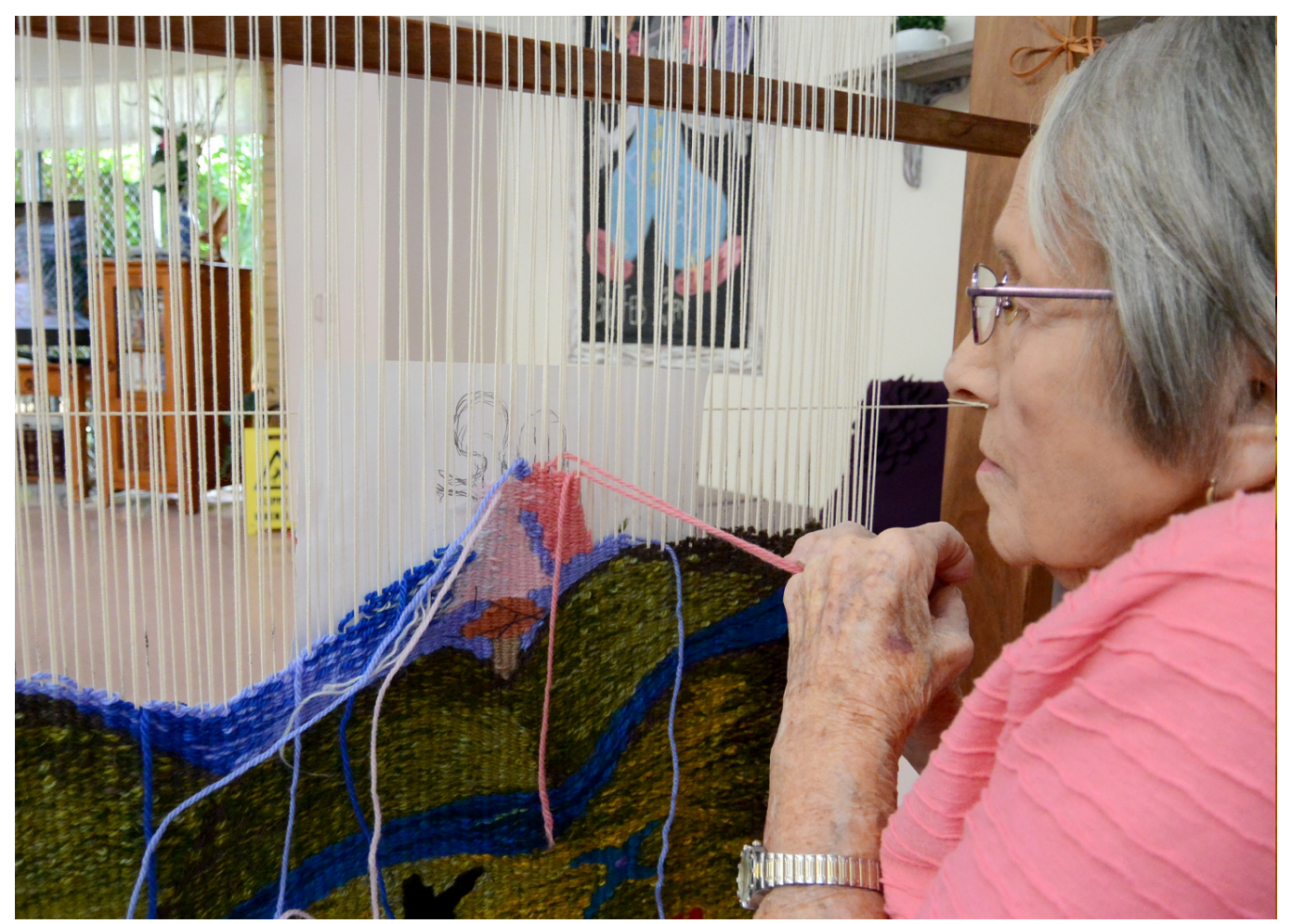

Figure 8. Lorna weaving her fairy

The experience of flow did not extent to every resident, however, creativity was triggered and nurtured individually. The loom and the weaving sometimes became a place 
where residents felt proud of their achievements, and open to sharing stories of their past lives. Rita often came with photos and embraced the opportunity to share her enthusiasm for photography. "I like taking photos," she told me proudly and requested: "Can we take photos with me while I am working on the tapestry?" (Figure 9). She also shared with me that her secret hope is that she could have the tapestry in her room, as she did not like the current decoration of it. This disclosure hints at other issues; despite best attempts to embrace person-centered care, it is always difficult for aged care providers to fully support individuality in the physical setting of a communal environment.

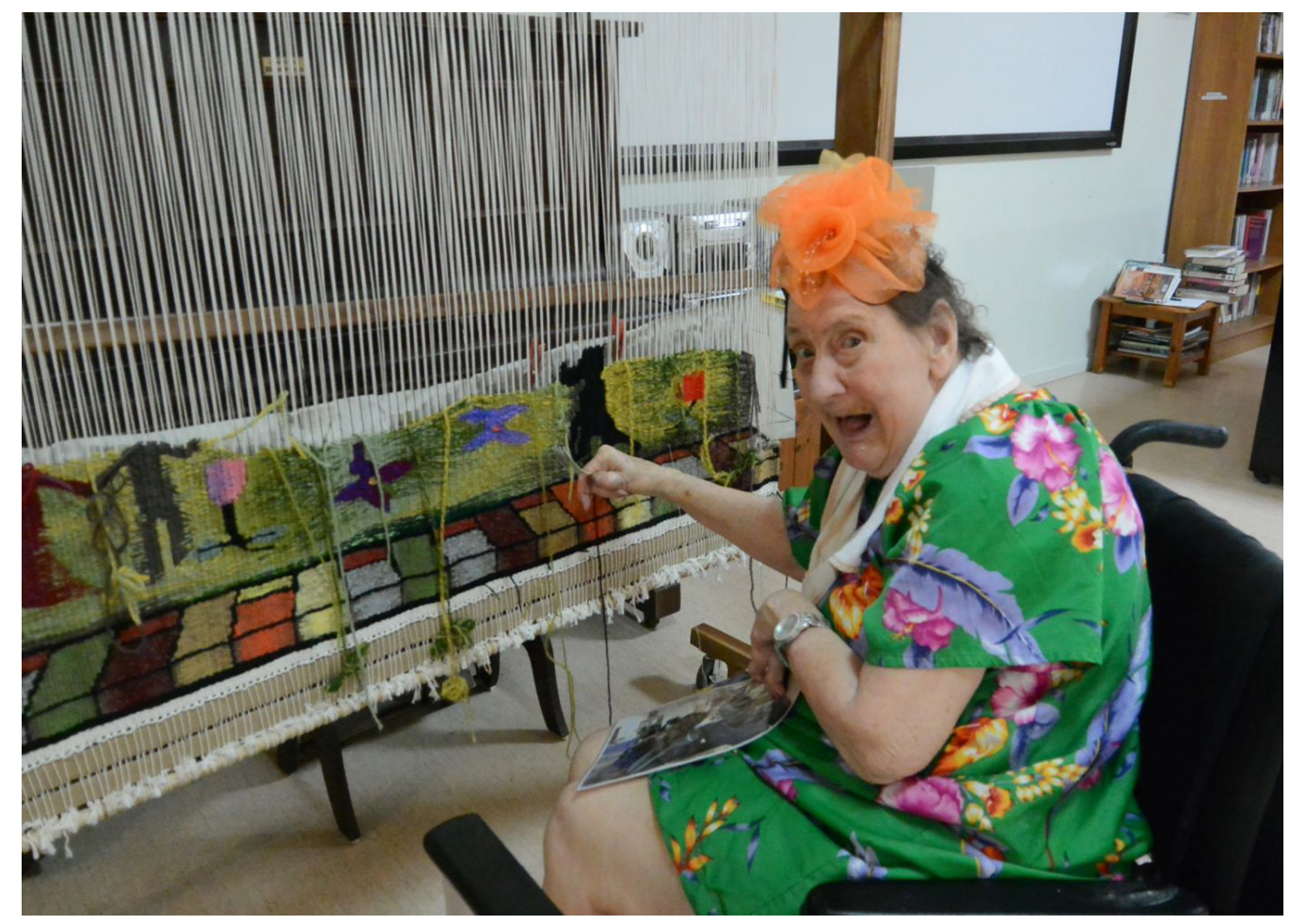

Figure 9. Rita holding her photo when she arrived to the loom

In the creation phase, there were always two chairs next to the artist where participants were able to sit and join the weaving. While there was always at least one person sitting at the loom, as Figure 10 and the field-notes below illustrate, some residents simply preferred to sit and watch the progress, rather than participating themselves. For some, the loom and the progressing tapestry became a place to enjoy watching and reflecting on the aesthetic elements of the work. The loom disrupted the daily routine of aged care, providing a safe space to watch, learn and, if desired, to engage in a novel craft.

... Pam was quietly watching from a distance and commented on the work "it is looking very nice." Other residents kept weaving and I invited Pam to sit at the loom. She strongly stated that she was only interested to watch and she did not want to work on it. I agreed and she kept talking about the colours, how beautiful the tapestry was, but she 
insisted on keeping a distance and remaining a spectator. I kept working and chatting to her about her interest in craft. She proudly told me that she had never been interested to do craft. She liked numbers. She used to work for a bank and she had loved it. While we were talking she slowly kept touching the tapestry and admiring it. I asked her to help me to separate some yarns and mix colours, which she was very happy to do and in the meantime her stories went back to her childhood. She said that the green colours of the tapestry were reminding her of her country Ireland and she told me a long story about her life and the journey of how she came to Australia after living in New Zealand. I kept weaving and listening to her and asked her again if she wanted to try to put some green yarn into the tapestry and she had a go. After a few lines she shyly said that she would rather watch me do it and her stories went on about her life (the war and her work) until lunchtime (10.10am, 13 Sept. 2016, fieldnotes IPD).

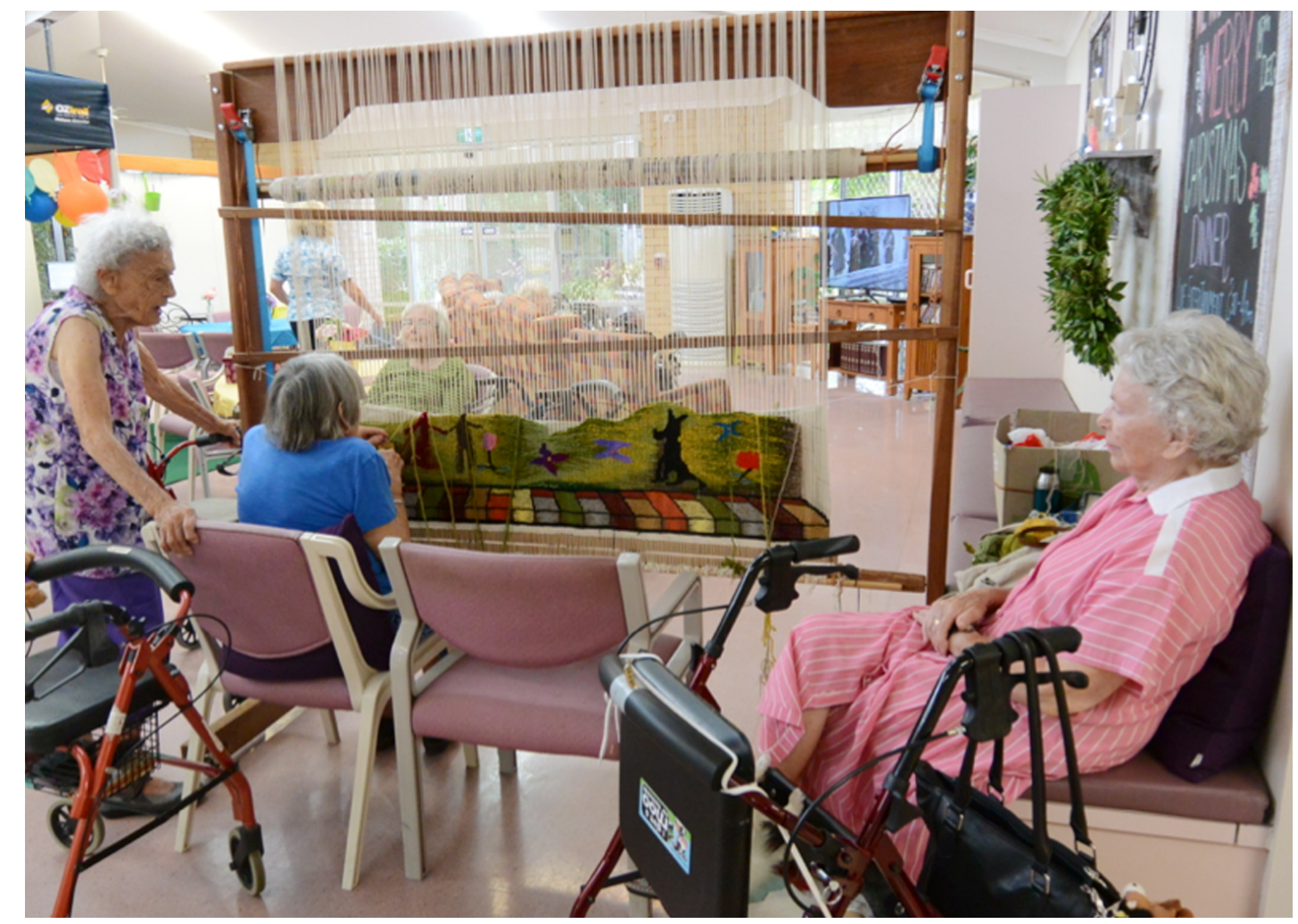

Figure 10. Pam watching from the distance

The story of Pam portrays one common form of engagement with the loom and the progressing tapestry: some residents liked to just sit and admire the work, and to talk about it. As Kim (2014, p. 62) reminds us, "the skill manifested in the quality of a craft object stirs in us admiration." Yet, the aesthetic responses of how people experience a craft encounter (whether it is by doing or watching) are rarely documented by researchers. Based on Kant's (1928) writings, McCloskey (1987, p. 29) describes the aesthetic experience as 
"disinterested pleasure," an emotional engagement with an object without wanting anything in return. The aesthetic response to the tapestry weaving often became a space where "elsewhere" could be projected; the "elsewhere" in most cases was a memory of an event or a home. For example, relatives sometimes brought their loved ones to the loom to stimulate conversation about the progressing tapestry. One visitor, Dave, brought his elderly mother Margo to look at the tapestry; Margo had lived in the facility for three years and her communication was seriously compromised. As Dave explained, "she was born in Scotland, my father used to do weaving...I hoped she might recognise the familiar activity and brighten her..." Unfortunately, due to compromised health as part of the ageing process, it was hard to see a direct response from Margo - something Tornstam (1997) describes as the biggest barriers of reaching transcendence in old age. In cases like Margo's, the impact and connection remained unknown to us, however, it was obvious that Dave was happy sharing something familiar from the past with his mother.

Similar to the connection phase, the loom was a place to communicate and share stories, triggered at this point by the progressing design. Darlaston (2013) describes similar experiences, where textile making (especially tapestry weaving) opened up a "third place" where communication and connection of past and current craft making could take place. This was specifically true for Beryl, a female resident who liked to see the progressing

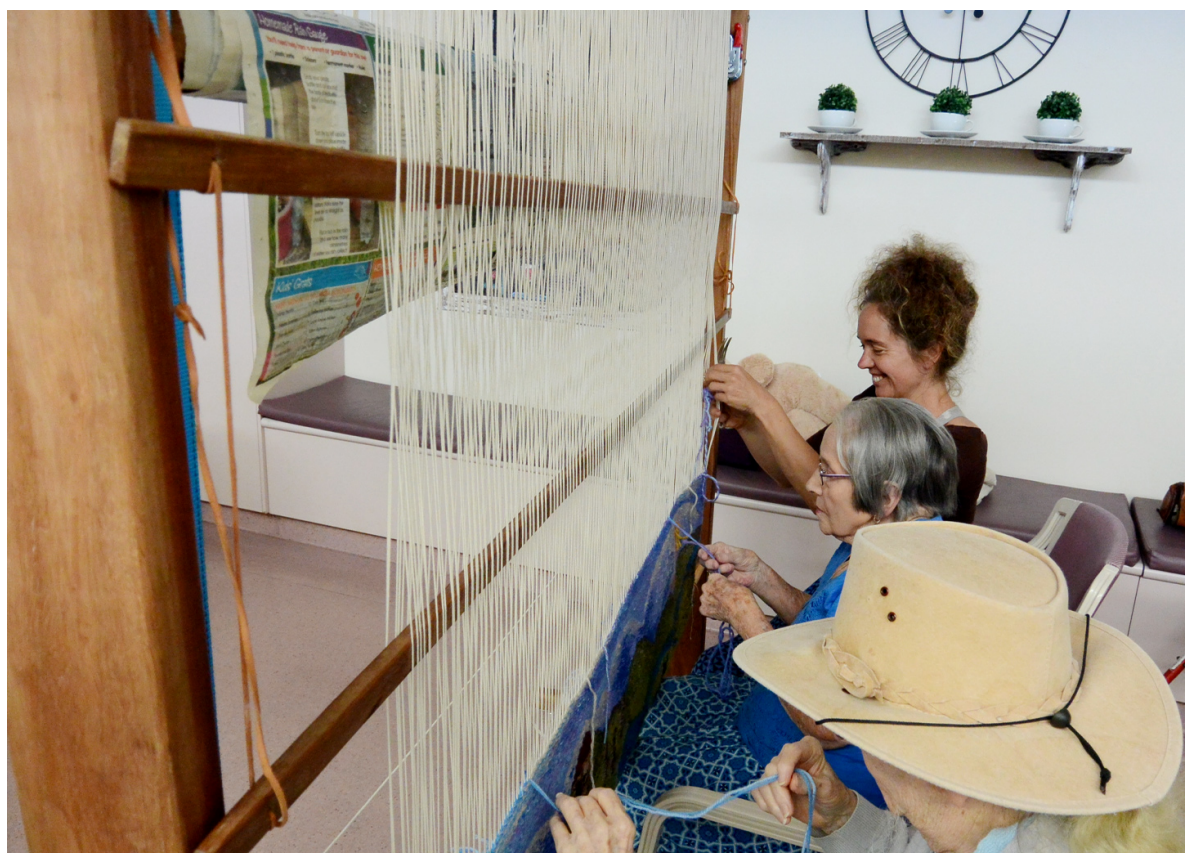

Figure 11. Beryl, Lorna and the Artist, weaving at the loom tapestry and have a chat about the design, week by week, when the loom was wheeled away. I always had to stop and show it to her. "It has changed a lot... it is coming together nicely," she responded often, while I grabbed the opportunity to invite her to join the weaving. She frequently replied, "I do not think I can do this." Yet, over time, she overcame her shyness and joined the weaving. This was a big change for Beryl, who lived an isolated life in a communal setting and rarely came to or participated in facility-organised activities. Yet, as Figure 11 illustrates, the novelty and the beautifully progressing colours opened up a "third place," where friendship and crafting made connections during the creation of the tapestry. 


\section{Discussion}

During six months, the Tapestry of Home project enabled numerous opportunities for engagement with a creative craft activity that became a meaningful activity, forming a sense of purpose (Frankl, 1992) and enabling expressions through making and communicating for all participants. The participants appreciated the loom with playfulness which was characterised by curiosity, imagination and experimentation, as they became designers and makers. Playfulness is an important concept as a catalyst of creativity (Loi \& Dillon, 2006) and aligns with the orientation of participatory art processes, which focus on the process rather than the product (Bishop, 2004), and with theories which emphasis more ludic and experimental manual craft (Gauntlett, 2011).

The tapestry project also has correlation to Gauntlett's (2011) concept of craft - that "making is connecting." He implies that craft making creates connection to both the physical threads that we engage with while making craft and connections that "give us a sense of wonder, agency, and the possibilities of the world" (p. 2). In our project, the craft participation connected successful collaboration between individuals, ideas and their materials that assisted transcendence, flow and resilience in old age. At the same time, the detailed descriptions highlighted the reality of the barriers in old age that influence participation, and how simply observing and engaging in reminiscence was valued (we have discussed this elsewhere, see Demecs \& Miller, 2018).

The loom also became a "safe place" for exchange. Carter (2004) describes creative making processes as exchange between the makers and the creative process. The tapestry project enabled exchanges between residents, staff and family members that reached back to past activities and memories formed in the present through working together at the loom and sharing previously undiscussed personal information with each other. The exchange also formulated through the tapestry practice as the information revealed to researchers and readers the world of individuals in the aged care home.

Overall, the project was welcomed by the residents as well as by the staff - from the management to the caring staff, as the presence of the craft studio positively altered the physical and social environment of the facility. Originally, the project was designed to involve everybody who wished to participate, including staff, and this was clearly explained in the project proposal. Thus, it was interesting to see that while they were very friendly and ready for conversations, none of the staff tried out the weaving process. They strongly felt that the project was for the residents. 


\section{Artist/Researcher Reflections}

The role of an artist within the participatory context has been described as being an "animateur," someone who creates an environment where people can enter a creative dialog and making (Dilkelmann, 2011). Taking the role of the "animateur" in the Tapestry of Home project has been a specifically rewarding experience, because I, llona, could share my passion with a socially neglected community to encourage and bring forward their narratives throughout engaging with a craft activity (see Figure 12 and 13). Additionally, it enabled me to promote a culture, as Gauntlett (2011, p. 8) described, of "making and doing," an approach which is more likely to enhance quality of life and engagement than the culture of "sit back and be told," which is unfortunately common within institutionalised life. My artistic practice facilitated interpersonal and creative safety. It reinforced my personal beliefs that art within a health care environment, not only fosters creativity, but also creates a safe, protective, non-clinical stage where people can express their positive self-identities and sociability.

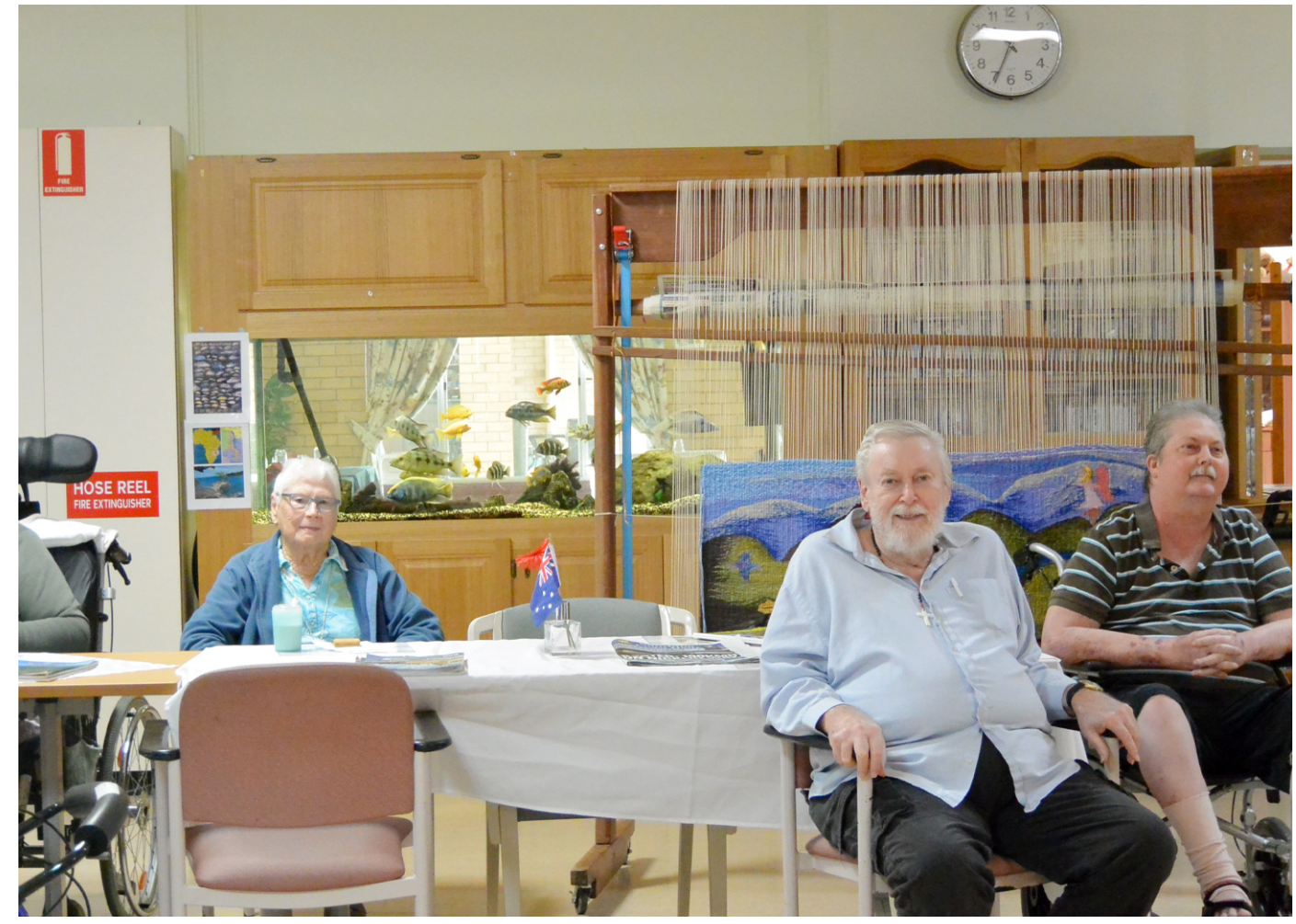

Figure 12. Nancy, Alpal and Jack, proud of their contributions to the tapestry 


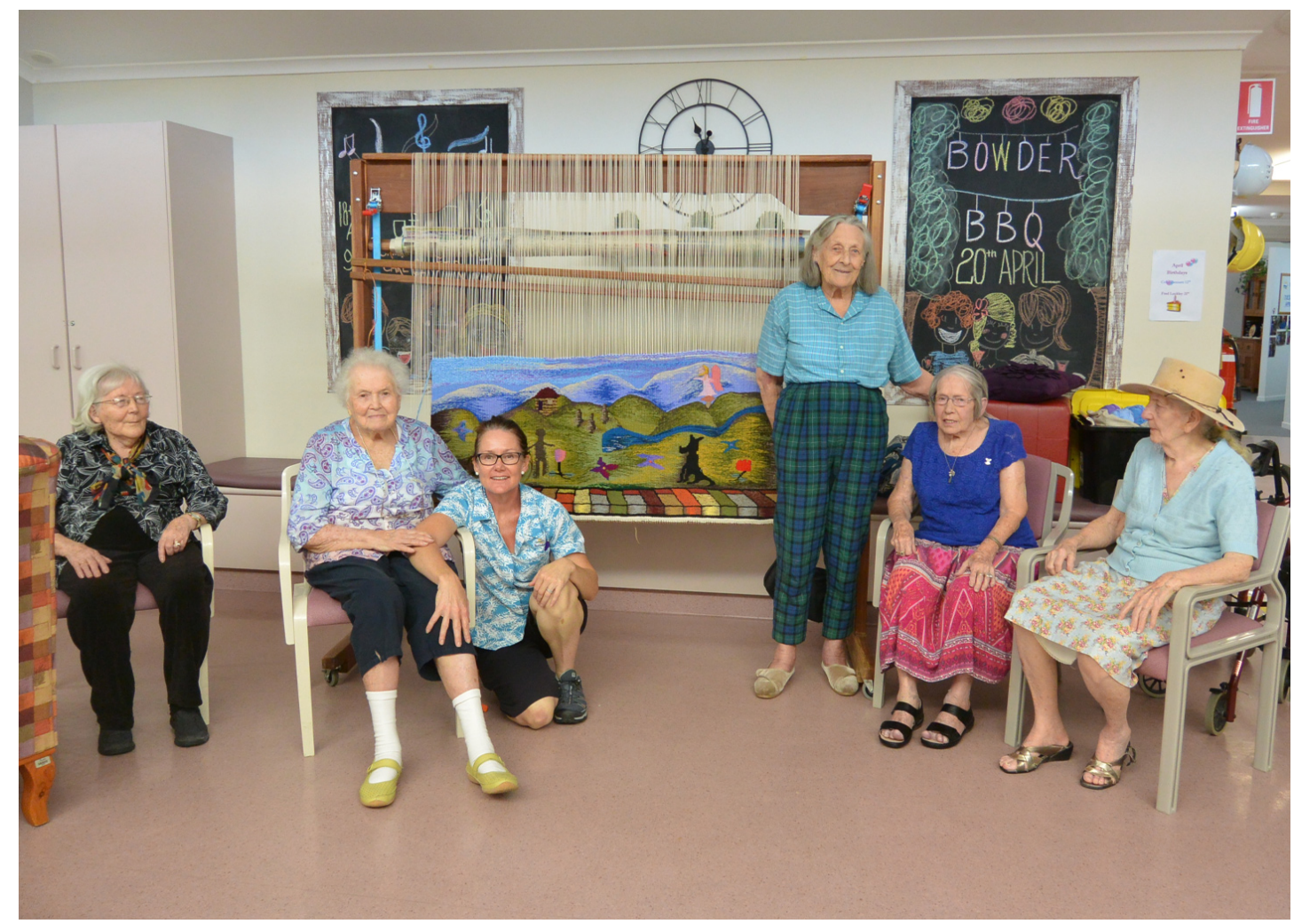

Figure 13. Some of the weavers

\section{In Closing}

This paper reflects the interactions and experience of a craft encounter in an aged care community, framed as a participatory art project presented through participants' narratives and photographs. As well as contributing to the literature on the value of creative leisure in community and aged care settings (e.g., Kenning, 2015; Maidment \& McFlare, 2011; Miller, 2016), this research makes a unique contribution as the first to deeply delve into the potential of participatory tapestry weaving in aged care. Aged care facilities are frequently viewed negatively, as sites of inactivity, boredom and isolation. The Tapestry of Home project is an innovative example of potential future of best practice. Just as childcare facilities are increasingly being co-located into the design of aged care to foster intergenerational connections and activities, perhaps artists and creative craft need to have a permanent space in aged care as well. The artist's studio is an important instrument for creativity and identity making, yet artists often struggle to find access to a permanent studio space (Sjoholm, 2018). Aged care might provide an unusual, yet welcoming, home. Contemporary aged care facilities typically have on-site coffee shops, gyms and pools (Miller \& Buys, 2007), with a growing a trend for co-located child care facilities; given the success of the Tapestry of Home project, aged care providers should consider integrating artists' studios 
into the design of these spaces. The impact could be positively transformative for artists, as well as for the residents, staff and visitors to aged care.

The final tapestry (Figure 14), full of metaphors and concrete symbols, provides a strong visual narrative about the meaning of home for older people living in aged care. This tapestry will live on as a collective memory; its intended final home is the walls of a university research centre and to date, the Tapestry of Home has been publicly exhibited at an aged care facility, library, forum and conference. By reflecting and sharing the positive experiences and impact of this collaborative co-creation process, we hope it raises community, and particularly artists', awareness about the value of participatory art projects in an aged care context.

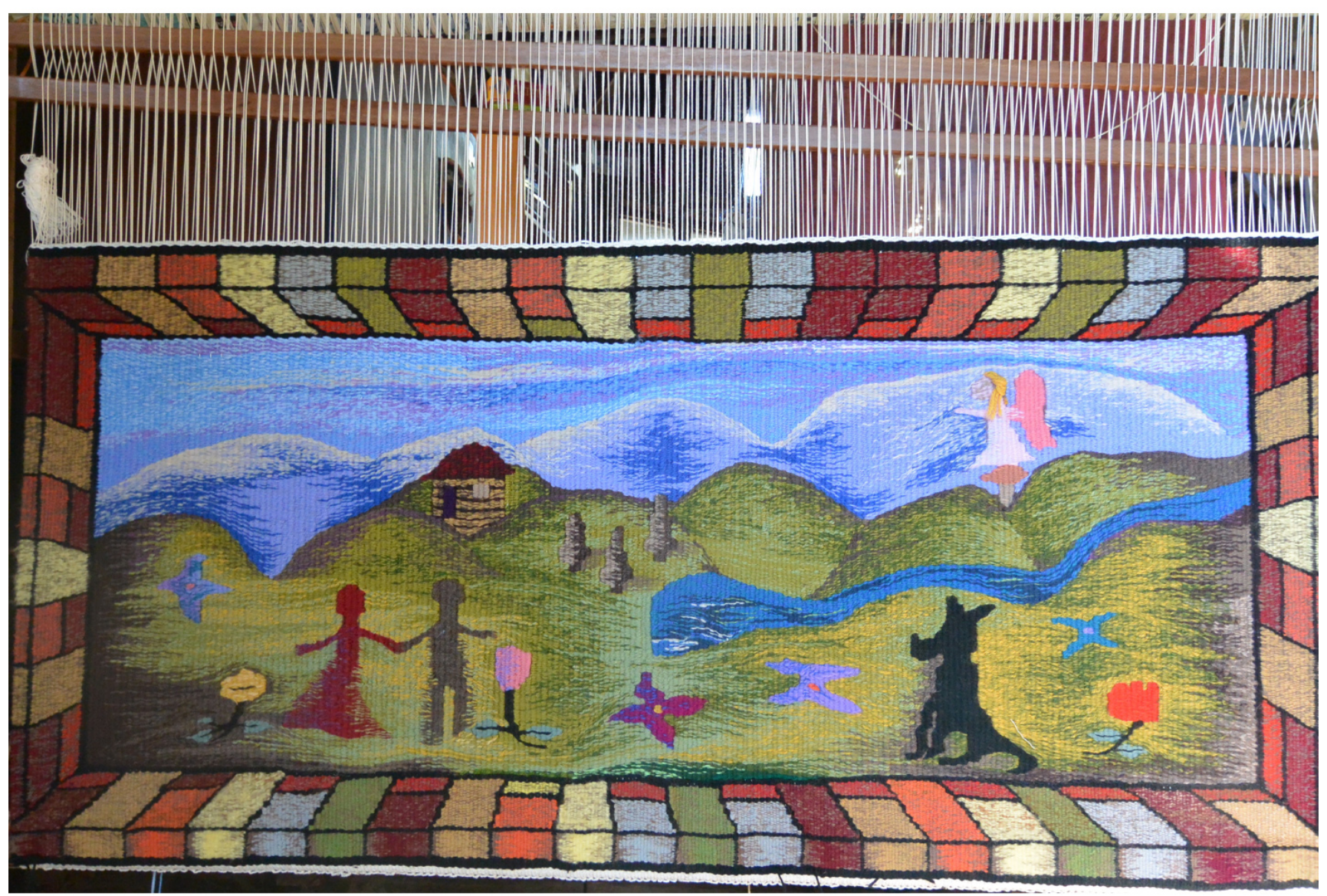

Figure 14. The final tapestry 


\section{Acknowledgements}

First of all, we would like to thank the participants who openly agreed to share their experiences with the researchers, as well as to Sundale Aged Care Provider in Nambour (on Australia's Sunshine Coast) for so kindly accommodating and supporting the Tapestry of Home artist in residence program. Thanks are also extended to the Australian Government, for their PhD scholarship (Australian Postgraduate Award) awarded to the first author. 


\section{REFERENCES}

Adeniji-Neil, D., Concannon-Gibney, T., \& Weida, C. (2014). Craft objects and storytelling. In L. Weida (Ed.), Crafting creativity \& creating craft (pp. 19-27). Rotterdam, NL: Sense Publisher.

Belford, P. (2013). Catalytic clothing and tactility factory: Crafted collaborative connections. In A. Ravetz, A. Kettle \& H. Felcey (Eds.), Collaboration through craft (pp. 129-143). London, UK: Bloomsbury.

Benjamin, W., \& Arendt, H. (1987). Illuminations. New York: Schocken Books.

Bishop, C. (2004). Antagonism and relational aesthetics. October Magazine 110, Fall, 51-79. Retrieved from:

Black, S. (2017) Knit + resist: Placing the Pussyhat Project in the context of craft activism. Gender, Place \& Culture, 24(5), 697-710.

Braun, V., \& Clarke, V. (2006). Using thematic analysis in psychology. Qualitative Research in Psychology, 3(2), 77-101. doi:10.1191/1478088706qp063oa

Carter, P. (2004). Material thinking: The theory and practice of creative research. Carlton, AU: Melbourne University Publishing.

Charmaz, K. (2004). Premises, principles, and practices in qualitative research: Revisiting the foundations. Qualitative Health Research, 14(7), 976-993. doi: $10.1177 / 1049732304266795$

Choi, N. G., Ransom, S., \& Wyllie, R. J. (2008). Depression in older nursing home residents: The influence of nursing home environmental stressors, coping, and acceptance of group and individual therapy. Aging \& Mental Health, 12(5), 536-547. doi: 10.1080/13607860802343001

Clandinin, D. J., \& Huber, J. (2010). Narrative inquiry. In P. Peterson, E. Baker \& B. McGaw (Eds.), International encyclopedia of education (pp.436-441). New York: Elsevier.

Cohen, G. D. (2009). New theories and research findings on the positive influence of music and art on health with ageing. Arts \& Health: An International Journal for Research, Policy and Practice, 1(1), 48-62. doi:10.1080/17533010802528033 
Csikszentmihalyi, M. (1996). Creativity: Flow and the psychology of discovery and invention. New York: Harper.

Darlaston, K. (2013). The generative loom: Tapestry in the community. Craft+Design Enquire, 4, 35-48.

Deacon, D. A., \& Calvin, P. E. (2014). War imagery in women's textiles: An international study of weaving, knitting, sewing, quilting, rug making and other fabric arts. Jefferson, NC: McFarland \& Company, Inc.

Demecs, I. P., \& Miller, E. (2018, Sept. 12). Participatory art in residential aged care: A visual and interpretative phenomenological analysis of older residents' engagement with tapestry weaving. Journal of Occupational Science. Advanced online publication. doi: 10.1080/14427591.2018.1515649

Desmarais, S. (2016). Affective materials: A processual, relational, and material ethnography of creative making in community and primary care groups (Doctoral dissertation). Falmouth University, UK. Retrieved from: http://ualresearchonline.arts.ac.uk/12308/1/ Desmarais\%202016THESIS\%20FINAL\%20PDF.pdf

Dinkelmann, C. Y. (2011). Stories of belonging-A tapestry of stories. Using narrative enquiry and visual art to investigate individual and collective identity with in a residential aged care facility. In B. J. Worsfold (Ed.), Acculturating age: Approaches to cultural gerontology (pp. 117-132). Catalunya, ES: University Lleida.

Erikson, E. H. (1950). Childhood and society. New York: W. W. Norton \& Company.

Ewens, T. (2009). Notes from Moon Rain Centre. fibreQuarterly Canada, 5(3/Fall). Retrieved from: http://www.velvethighway.com/joomla/index.php? option=com content\&task=view\&id=149

Gauntlett, D. (2011). Making is connecting. The social meaning of creativity from DIY and knitting to YouTube and Web 2.0. Cambridge, UK: Polity Press.

Hogan, S. (2015). Mothers make art: Using participatory art to explore the transition to motherhood. Journal of Applied Arts \& Health, 6(1), 23-32, doi:10.1386/jaah.6.1.23_1 
Higgs, P., \& Gilleard, C. (2014). Frailty, abjection and the "othering" of the fourth age. Health Sociology Review, 23(1), 10-19.

Kant, I. (1928). The critique of judgment. (J. C. Meredith, Trans.). Oxford, UK: Oxford University Press.

Kenning, G. (2015). "Fiddling with threads": Craft-based textile activities and positive wellbeing. Textile, 13(1), 50-65.

Kim, K. H. (2016). The creativity challenge: How we can recapture American innovation. New York, NY: Prometheus Books.

Kim, N. (2014). Conceptual, biological and historical analyses of craft. In L. Weida (Ed.), Crafting creativity \& creating craft (pp. 61-76). Rotterdam, NL: Sense Publisher.

Leslie, E. (1998). Walter Benjamin: Traces of craft. Journal of Design History, 11(1), 5-13.

Lindsay, S. (n.d.). Down south: Tapestry in Australia. Retrieved from: http://americantapestryalliance.org/exhibitions/tex_ata/down-south-tapestry-inaustralia/

Loi, D., \& Dillon, P. (2006). Adaptive educational environments as creative spaces. Cambridge Journal of Education, 36(3), 363-381.

Frankl, V. E. (1992). Man's search for meaning (4th ed.). Boston, MA: Beacon Press.

Fraser, A., Bungay, H., \& Munn-Giddings, C. (2014). The value of the use of participatory arts activities in residential care settings to enhance the well-being and quality of life of older people: A rapid review of the literature. Arts \& Health: An International Journal for Research, Policy and Practice, 6(3), 266-278. doi:10.1080/17533015.2014.923008

Maidment, J., \& Macfarlane, S. (2011). Older women and craft: Extending educational horizons in considering wellbeing. Social Work Education, 30(6), 700-711.

McCloskey, M. A. (1987). The first moment — Disinterested pleasure. In M. A. McCloskey, Kant's aesthetic (pp. 29-39). London, UK: Palgrave Macmillan.

McHugh, M. C. (2016). Experiencing flow: Creativity and meaningful task engagement for senior women. Women \&Therapy, 39(3-4), 280-295. 
Miller, E. (2016). Beyond Bingo? A phenomenographic exploration of leisure in aged care. Journal of Leisure Research, 48(1), 35-49.

Miller, E. \& Buys, L. (2007). Predicting older Australians leisure-time physical activity: Impact of residence, retirement village vs. community, on walking, swimming, dancing and lawn bowls. Activities, Adaptation \& Aging, 31(3), 13-30.

National Institute for Health and Care Excellence (NICE). (2013). Mental wellbeing of older people in care homes. Retrieved from: https://www.nice.org.uk/guidance/qs50

Nolan, M. R. (1996). Developing a knowledge base in gerontological nursing: A critical appraisal. In L. Wade \& K. Waters (Eds.), A textbook of gerontological nursing (pp. 210-237). London, UK: Baillière Tindall.

O'Neill, M. (2008). Transnational refugees: The transformative role of art? Forum: Qualitative Social Research, 9(2), Art 59. Retrieved from: http://www.qualitative-research.net/index.php/fqs/article/view/403/873

Penney, C. (Ed.). (2011). Tapestry a woven narrative. London, UK: Black Dog Publishing.

Pöllänen, S. (2015). Elements of crafts that enhance well-being: Textile craft makers' descriptions of their leisure activity. Journal of Leisure Research, 47(1), 58-78.

Prince, D., \& Butler, D. (2007). Clarity final report: Aging in place in America. Nashville, TN: Prince Market Research.

Productivity Commission. (2011). Caring for older Australians. Canberra, AU: Inquiry Report Australian Government. Retrieved from: https://www.pc.gov.au/inquiries/completed/aged-care

Reynolds, F., \& Prior, S. (2006). The role of art-making in identity maintenance: Case studies of people living with cancer. European Journal of Cancer Care, 15(4), 333-341. doi: 10.1111/j.1365-2354.2006.00663.x

Reynolds, F. (1999). Cognitive behavioural counselling of unresolved grief through therapeutic adjustment of tapestry-making. The Arts of Psychotherapy, 26(3), 165-171. 
Reynolds, F. (2000) Managing depression through needlecraft creative activities: A qualitative study. The Arts in Psychotherapy, 27(2), 107-114.

Riessman, C. K. (2008). Narrative methods for the human sciences. London, UK: Sage.

Riley, J., Corkhill, B., \& Morris C. (2013). The benefits of knitting for personal and social wellbeing in adulthood: Findings from an international survey. British Journal of Occupational Therapy, 76(2), 50-57.

Riley, J. (2008). Weaving an enhanced sense of self and a collective sense of self through creative textile-making. Journal of Occupational Science, 15(2), 63-73. doi: 10.1080/14427591.2008.9686611

Sjoholm, J. (2018). Making bodies, making space and making memory in artistic practice. In L. Price \& H. Hawkins (Eds.), Geographies of making craft and creativity (pp. 47-59). New York, NY: Routledge.

Timonen, V., \& O'Dwyer, C. (2009). Living in institutional care: Residents' experiences and coping strategies. Social Work in Health Care, 48, 597-613. doi: 10.1080/00981380902791267

Tornstam, L. (1997). Gerotranscendence: The contemplative dimension of aging. Journal of Aging Studies, 11(2), 143-154.

Turney, J. (2009). The culture of knitting. Oxford, UK: Berg. 


\section{ENDNOTES}

1 General craft includes knitting, painting on wood, bead making, quilting, sewing and embroidery. Many of these forms were once normal domestic practices of everyday life. Studio craft requires a high level of craft skill, usually attached to formal education. It aspires to be fine art, and maintains high standards in execution and design; examples are jewelry, glass, ceramic, textile. 